\title{
Modelo de gestión para el turismo rural en la zona centro de Manabí, Ecuador
}

\section{Management model for rural tourism in the central area of Manabí, Ecuador}

\section{Modelo de gestão do turismo rural na área central de Manabí, no Equador}

\author{
Jhonny P. Bayas-Escudero ${ }^{\text {I }}$ \\ johnnybayas@gmail.com \\ María C. Mendoza-Torres II \\ cristinamendoza30@hotmail.com
}

Recibido: 5 de octubre de 2017 * Corregido: 18 de noviembre de 2017 * Aceptado: 13 de enero de 2018

\footnotetext{
${ }^{\mathrm{I}}$ Magister en Gerencia de Proyectos de Ecoturismo, Diploma Superior en Investigación Científica y Asesoría Académica, Licenciado en Administración de Empresas de Turismo, Escuela Superior Politécnica Agropecuaria de Manabí Manuel Félix López, Portoviejo, Ecuador.

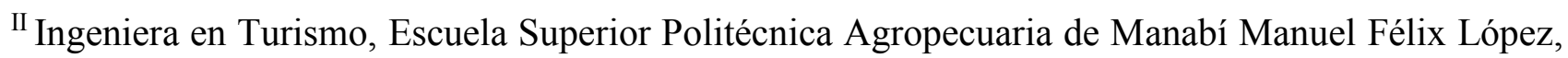
Portoviejo, Ecuador.
} 


\section{Resumen}

El objetivo de esta investigación fue diseñar un modelo de gestión turística para fomentar el turismo rural en la zona centro de la provincia de Manabí, para lo cual se plantearon tres fases: La primera se refirió al diagnóstico de la gestión turística; que se basó en la descripción del territorio en estudio; además de la obtención de criterios ofrecidos por los actores involucrados en dicha modalidad que se estableció mediante la aplicación de la matriz de involucrados y entrevistas dirigidas a los principales actores; además se elaboró la matriz de potencialidades turísticas y la matriz FODA; las cuales ayudaron a obtener como resultado primordial la información de la gestión actual que llevan cada uno de los emprendimientos turísticos y territorios enmarcados en la investigación. En la segunda fase se fundamentó en determinar los indicadores de gestión sostenible, mediante la matriz de indicadores con la ayuda de la revisión bibliográfica y la observación directa, teniendo como referente la certificación Biosphere y los criterios globales de turismo sostenible; y como última fase se estructuró el modelo de gestión, posteriormente se detalló la operatividad de los actores en los destinos turísticos para llevar a cabo la evaluación y control de las actividades y proceso a ejecutar; estableciendo el método de expertos con la intensión de proporcionar óptimos resultados en la adecuada planificación durante la gestión de cada destino turístico rural.

Palabras clave: desarrollo rural; gestión turística; gestión de destinos turísticos; sostenibilidad; turismo rural.

\section{Abstract}

The objective of this research was to design a model of tourism management to promote rural tourism in the central area of the province of Manabí, for which three phases were proposed: The first one referred to the diagnosis of tourism management; which was based on the description of the territory under study; besides obtaining the criteria offered by the actors involved in this modality that was established through the application of the matrix of stakeholders and interviews directed to the main actors; In addition, the tourism potential matrix and the SWOT matrix were prepared; which helped to obtain as a primary result the information of the current management carried out by each of the tourist undertakings and territories framed in the investigation. In the second phase, it was based on 

of bibliographic review and direct observation, taking as reference the Biosphere certification and the global criteria of sustainable tourism; and as the last phase the management model was structured, later the operability of the actors in the tourist destinations was detailed to carry out the evaluation and control of the activities and process to be executed; establishing the expert method with the intention of providing optimal results in the proper planning during the management of each rural tourist destination.

Keywords: rural development; tourism management; management of tourist destinations; sustainability; rural tourism.

\section{Resumo}

O objetivo desta pesquisa foi projetar um modelo de gestão do turismo para promover o turismo rural na área central da província de Manabí, para o qual três fases foram propostas: A primeira se refere ao diagnóstico da gestão do turismo; que foi baseado na descrição do território em estudo; além de obter os critérios oferecidos pelos atores envolvidos nessa modalidade que foi estabelecida por meio da aplicação da matriz de stakeholders e entrevistas direcionadas aos principais atores; Além disso, a matriz do potencial turístico e a matriz SWOT foram preparadas; que ajudou a obter como resultado primário as informações da atual administração realizada por cada uma das empresas e territórios turísticos enquadrados na investigação. Na segunda fase, baseou-se na determinação dos indicadores de gestão sustentável, por meio da matriz de indicadores, com auxílio de revisão bibliográfica e observação direta, tomando como referência a certificação da Biosfera e os critérios globais de turismo sustentável; e como última fase o modelo de gestão foi estruturado, posteriormente a operacionalidade dos atores nos destinos turísticos foi detalhada para realizar a avaliação e controle das atividades e processos a serem executados; estabelecer o método pericial com a intenção de fornecer ótimos resultados no planejamento adequado durante a gestão de cada destino turístico rural.

Palavras chave: desenvolvimento rural; gestão do turismo; gestão de destinos turísticos; sustentabilidade; turismo rural.

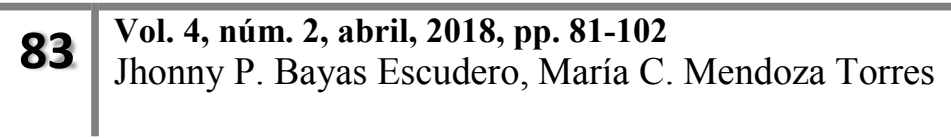




\section{Introducción}

La gestión turística es uno de los temas más importantes en la actualidad, debido a que busca garantizar la eficacia en la administración de las actividades, enfocándose en mejorar las condiciones de vida de las comunidades y el éxito del turismo. Para Domínguez R-Batista G, et al., (2013) es una alternativa en la que intervienen los actores locales en el dinamismo de estrategias socioculturales que hagan posible administrar de forma eficiente. De la misma manera Sánchez J. (2014) coincide en el dinamismo de la gestión de los recursos como un sistema cambiante, y de continua transformación, que se hace complejo debido a las múltiples interacciones por parte de las instituciones competentes en la toma de decisiones. Para esto es necesario hacer énfasis en que la gestión repercute en el uso responsable de los recursos naturales y culturales, indicando que la planificación y gestión son procesos fundamentales para el desarrollo sostenible. Mientras Moreno A. (2012) indica que la gestión turística de un destino necesita un grado mayor de desarrollo para asumir procesos integrales de implantación de políticas turísticas; sin duda el gran reto para el destino en el futuro; ambos autores manifiestan que la gestión requiere asociar esfuerzos a distintos niveles, sea local, provincial, nacional, para poder complementar una eficiente planificación, organización y control de actividades.

De acuerdo al objeto de estudio, la poca importancia hacia los procesos de planificación existente en la provincia de Manabí, conllevan a una deficiente gestión. Tomando en cuenta ésta problemática se debe considerar al turismo rural de forma responsable, por lo cual se hace imprescindible el uso de un modelo de gestión que permita mejorar el desarrollo de la actividad turística estructurando estrategias e indicadores, que permitan medir y obtener resultados óptimos (Ascanio A, 2014). Considerando lo antes mencionado, cabe resaltar la importancia del modelo de gestión porque busca mejorar el desarrollo turístico a través de un instrumento técnico, vinculado a las nuevas modalidades del turismo, que permita ofrecer servicios de calidad a los turistas y mejorar la calidad de vida de la población. (Balagué J y Navinés F. 2012).

Félix G y Doumet Y (2016), identifican los componentes de la planificación y gestión, donde se debe realizar un estudio que parte desde el análisis de los recursos naturales y culturales, la implementación las facilidades turísticas, la búsqueda del financiamiento e inversión por parte de las comunidades y 
Modelo de gestión para el turismo rural en la zona centro de Manabí, Ecuador

el estudio del mercado en general. Siendo los órganos principales para la gestión turística rural los Gobiernos Autónomos Descentralizados y los Departamentos de Turismo de la provincia, sin dejar aquellos órganos de apoyo como son las juntas parroquiales rurales, ya que se encuentran en la realidad de las comunidades, ofreciendo bienestar y calidad que permita gestionar los recursos naturales y culturales existentes (Reyes M-Manjarrez N et al., 2014).

Lo anterior implica que la gestión turística es para el bienestar de las localidades en general, Agüera F y Morales P. (2015) mencionan que existen oportunidades para nuevos tipos de turismo como un nuevo producto con las peculiaridades inherentes a su comercialización, estas oportunidades están adquiriendo en los últimos tiempos un papel dinamizador socioeconómico y favorecedor del desarrollo local, a través de su explotación como una nueva forma de turismo. Además, Flores D y Barroso M. (2012) describen al turismo rural como un tipo de estrategia que ayuda a dinamizar los procesos en el desarrollo sostenible de los recursos por la interacción entre el ambiente y la población en general.

Las comunidades rurales tienen una importancia fundamental en el desarrollo socio-económico del área, sosteniéndose también una teoría del intercambio social tanto de los comuneros, del turista y los gestores locales, cooperando al desarrollo a través del turismo.

Evidenciando lo descrito, en las comunidades donde se encuentra cada uno de los emprendimientos turísticos rurales de la parte centro de la provincia de Manabí, tienen el propósito de encontrar posibilidades de desarrollo mediante la actividad turística, y mejor aun llevando una adecuada gestión de los recursos donde se obtengan mejores beneficios para la colectividad en general. Indicando que el turismo en las zonas rurales puede llegar a ser un transformador de la pobreza y crear un desarrollo económico de las localidades de la provincia donde se lleva a cabo el trabajo de investigación.

Para Estrada A y Ranfla A (2015) en el turismo participan un conjunto de actividades que pueden actuar en beneficio de la sostenibilidad de los destinos en especial de comunidades rurales, debido a la actual demanda por obtener estos productos turísticos rurales donde involucren a la comunidad receptora dándoles la importancia debida; respecto a la relación del turismo y la sostenibilidad

85 Vol. 4, núm. 2, abril, 2018, pp. 81-102

Jhonny P. Bayas Escudero, María C. Mendoza Torres 
Modelo de gestión para el turismo rural en la zona centro de Manabí, Ecuador

manifiestan un gran número de investigadores en la actualidad el desarrollo turístico está siendo guiado por los principios de sostenibilidad, sobre todo a partir de la década de los ochenta, con el crecimiento del turismo de masas y los efectos negativos producidos por este tipo de turismo.

De allí la necesidad de implementar modelos de gestión que fomenten el turismo rural en la zona centro de Manabí, ya que sirven como guía para los actores públicos entre ellos las direcciones de turismo y de los actores privados como los emprendedores de los lugares de interés turístico; aprovechando de manera óptima y sostenible los recursos naturales y culturales; mejorando la calidad de vida de las comunidades rurales.

\section{Materiales y métodos}

La ejecución del modelo de gestión se realizó desde el mes de agosto de 2016 hasta marzo de 2017, en la zona centro de la provincia de Manabí, ubicada actualmente dentro de la zona de Planificación 4, cuenta con $18.870 \mathrm{~K} \mathrm{~m}^{2}$ aproximadamente. Limita al norte con la provincia de Esmeraldas, al sur con las provincias de Santa Elena y Guayas, al este con las provincias de Guayas, Los Ríos y Santo Domingo de los Tsáchilas, y al oeste con el Océano Pacifico. Tiene 1'345.779 habitantes, lo que representa el 79\% de la población de esta Región y el 9,4\% de los habitantes del Ecuador. El 63\% de las personas vive en zonas urbanas y el $37 \%$ en zonas rurales. Los procedimientos referenciados para el modelo de gestión son los de: Avella L. (2004), Merinero R y Pulido J. (2009), Plaza D. (2013), Campos B y González M. (2015).

\section{Fase I. Diagnóstico situacional}

De acuerdo a los instrumentos necesarios se procedió a realizar una matriz de involucrados que se basa en describir actores implicados, interés sobre la problemática, problemas percibidos, recursos y mandatos, intereses sobre el proyecto y conflictos potenciales, esta fue aplicada a 5 actores públicos involucrados en la gestión turística y 6 entrevistas a propietarios de establecimientos de los diferentes cantones tomados como objeto de estudio, con el propósito de obtener información sobre la gestión que se está llevando en los lugares de interés turístico. Además, se aplicó la matriz de potencialidades

\footnotetext{
86

Vol. 4, núm. 2, abril, 2018, pp. 81-102

Jhonny P. Bayas Escudero, María C. Mendoza Torres
} 
Modelo de gestión para el turismo rural en la zona centro de Manabí, Ecuador

donde se establecieron los caracteres (cultural, ambiental, paisajístico y deportivo) y atributos (dinámica, utilización, accesibilidad y equipamiento turístico) de los sitios de interés turístico para darle una escala valorativa a cada uno de ellos.

Para finalizar con el diagnóstico, se realizó la matriz FODA detallando las fortalezas, oportunidades, debilidades y amenazas del territorio en estudio, para luego realizar una valoración ponderada con el fin de describir las principales falencias y beneficios; además de determinar el problema general, la solución y sus respectivas estrategias.

\section{Fase II. Principios e indicadores de gestión sostenible}

Se establecieron revisiones y análisis bibliográficos de acorde a los parámetros expuestos en los lugares de interés turístico en relación con los pilares de los criterios globales establecidos por el Consejo Global de Turismo Sostenible, estableciendo una matriz de indicadores de gestión donde se indicaron posibilidades como medios de verificación y sus respectivos responsables.

\section{Fase III. Modelo de gestión turística}

Para el diseño del modelo de gestión sostenible se establecieron objetivos, misión, visión, valores y metas corporativas, además de la implementación de una matriz de estrategias donde se establecieron los objetivos y actividades correspondientes para llevar a cabo un adecuado seguimiento del proceso de gestión. Por último, para dar mayor valor al trabajo de investigación se aplicó el método de expertos, donde se realizó el análisis de la propuesta del modelo de gestión y de cada uno de sus componentes.

\section{Resultados y Discusión}

\section{Fase I. Diagnóstico situacional}

En base a la matriz de involucrados, se seleccionaron los representantes principales con el fin de conocer su criterio sobre la gestión turística rural. Los principales problemas percibidos se dan la falta de vinculación social e interrelación institucional. Ya que son problemas notorios que se encuentran

\section{7}

Vol. 4, núm. 2, abril, 2018, pp. 81-102

Jhonny P. Bayas Escudero, María C. Mendoza Torres 
Dom. Cien., ISSN: $2477-8818$

Vol. 4, núm. 2, abril, 2018, pp. 81-102

Modelo de gestión para el turismo rural en la zona centro de Manabí, Ecuador

reflejados en los establecimientos y sitios de interés turístico, lo cual se evidencia desde los altos rangos de coordinación; los mismos que tienen la capacidad de contribuir con una adecuada gestión de los destinos y localidades de la provincia de Manabí; para efecto están en la disposición de apoyar al desarrollo de los destinos, ya que se enfocan principalmente en la matriz productiva, siendo el turismo una de las fuentes generadoras de ingresos y en si bienestar social. Manteniendo en cuenta los conflictos potenciales que se dan en primer lugar por la falta de organización desde las entidades provinciales hasta los sectores locales de los destinos; de tal manera que se generan conflictos de integración turística, por lo cual se deben establecer y mantener acuerdos de integración social (Cuadro 1).

Cuadro 1. Matriz de actores involucrados

\begin{tabular}{|c|c|c|c|c|c|}
\hline Actores & $\begin{array}{c}\text { Intereses sobre la } \\
\text { problemática }\end{array}$ & $\begin{array}{l}\text { Problemas } \\
\text { percibidos }\end{array}$ & $\begin{array}{l}\text { Recursos y } \\
\text { mandatos }\end{array}$ & $\begin{array}{c}\text { Intereses sobre el } \\
\text { proyecto }\end{array}$ & $\begin{array}{l}\text { Conflictos } \\
\text { potenciales }\end{array}$ \\
\hline $\begin{array}{l}\text { Ministerio de } \\
\text { turismo }\end{array}$ & $\begin{array}{l}\text { Se basa en el Desarrollo } \\
\text { sostenible, consciente y } \\
\text { competitivo del sector, } \\
\text { ejerciendo sus roles de } \\
\text { regulación, planificación, } \\
\text { gestión, promoción, difusión } \\
\text { y control. }\end{array}$ & $\begin{array}{c}\text { Falta de } \\
\text { planificación } \\
\text { turística }\end{array}$ & $\begin{array}{c}\text { Capacidad para } \\
\text { contribuir en la } \\
\text { equidad entre } \\
\text { los factores de } \\
\text { sostenibilidad }\end{array}$ & $\begin{array}{l}\text { Apoya el sistema } \\
\text { de la planificación } \\
\text { en cuanto a la } \\
\text { gestión del turismo } \\
\text { de acuerdo a la } \\
\text { matriz productiva }\end{array}$ & $\begin{array}{c}\text { Conflictos de } \\
\text { Organización desde } \\
\text { las entidades } \\
\text { provinciales hasta } \\
\text { sectores locales de } \\
\text { los destinos }\end{array}$ \\
\hline $\begin{array}{c}\text { GADs } \\
\text { cantonales }\end{array}$ & $\begin{array}{l}\text { Gozan de autonomía política, } \\
\text { administrativa y financiera, y } \\
\text { están regidos por los } \\
\text { principios de solidaridad, } \\
\text { subsidiariedad, equidad, } \\
\text { interterritorial, integración y } \\
\text { participación ciudadana. }\end{array}$ & $\begin{array}{c}\text { Falta de } \\
\text { vinculación } \\
\text { social }\end{array}$ & $\begin{array}{l}\text { Capacidad de } \\
\text { gestión. } \\
\text { Accesibilidad } \\
\text { vial. }\end{array}$ & $\begin{array}{c}\text { Mayor } \\
\text { productividad } \\
\text { social y económica } \\
\text { en la localidad }\end{array}$ & $\begin{array}{l}\text { Conflictos de } \\
\text { planificación } \\
\text { turística }\end{array}$ \\
\hline $\begin{array}{c}\text { GADs } \\
\text { parroquiales } \\
\text { rurales }\end{array}$ & $\begin{array}{l}\text { Promueven el desarrollo } \\
\text { sostenible y la equidad de una } \\
\text { determinada localidad. }\end{array}$ & $\begin{array}{c}\text { Falta de } \\
\text { vinculación } \\
\text { social }\end{array}$ & $\begin{array}{l}\text { Capacidad de } \\
\text { organización y } \\
\text { control de las } \\
\text { comunidades }\end{array}$ & $\begin{array}{l}\text { Mejor calidad de } \\
\text { vida de los } \\
\text { pobladores }\end{array}$ & $\begin{array}{c}\text { Conflictos de } \\
\text { integración social }\end{array}$ \\
\hline $\begin{array}{c}\text { Empresas } \\
\text { turísticas } \\
\text { comunitarias }\end{array}$ & $\begin{array}{l}\text { Promueven, desarrollan y } \\
\text { comercializan } \\
\text { turísticos integrados a los } \\
\text { atractivos } \\
\text { sostenibles. }\end{array}$ & $\begin{array}{c}\text { Deficiente } \\
\text { interrelación } \\
\text { institucional }\end{array}$ & $\begin{array}{l}\text { Capacidad de } \\
\text { Organización } \\
\text { turística }\end{array}$ & $\begin{array}{l}\text { Apoya el sistema } \\
\text { de gestión de los } \\
\text { destinos turísticos }\end{array}$ & $\begin{array}{c}\text { Conflictos de } \\
\text { integración turística }\end{array}$ \\
\hline
\end{tabular}

\section{8}

Vol. 4, núm. 2, abril, 2018, pp. 81-102

Jhonny P. Bayas Escudero, María C. Mendoza Torres 
Modelo de gestión para el turismo rural en la zona centro de Manabí, Ecuador

Por otra parte, la aplicación de entrevistas sirvió para conocer la gestión actual que se lleva en cada cantón (Junín, Bolívar, Chone y Tosagua) donde se encuentran ubicados los emprendimientos relacionados a la actividad rural. Los resultados reflejaron la deficiente gestión de los recursos y en sí de la actividad turística; debido a las limitaciones, principalmente de carácter económico, los entes públicos únicamente apoyan la realización de actividades como ferias, talleres y festivales para dar a conocer la riqueza cultural de los pueblos como aporte al desarrollo del turismo en los cantones referentes, por lo que mantiene potencial de los recursos y de las actividades agropecuarias.

Posteriormente, se obtuvo los criterios de gestión de varios emprendimientos turísticos rurales de la zona centro de la provincia; los cuales evidenciaron las deficiencias de organización y gestión de los recursos, a excepciones de ciertos establecimientos que tienen ciertas iniciativas de desarrollo; pero todos mantienen las potencialidades para ejercer actividades agro turísticas en combinación con la adecuada gestión sostenible.

Por lo cual se sustenta la necesidad e importancia de un modelo de gestión para los mencionados establecimientos. Cabe recalcar el interés por parte de los representantes privados quienes están de acuerdo con aplicar un modelo que les indiquen como mejorar su actividad, además de las estrategias a seguir para un mayor desarrollo turístico rural, que implica el necesario el apoyo de los actores involucrados desde el nivel local y provincial.

Continuando con el proceso de investigación, se aplicó la matriz de potencialidades turísticas propuesta por Villegas F. (2000), que sirvió para dar prioridad a los sitios y/o emprendimientos de mayor interés turístico considerando primero el Carácter, que engloba lo (cultural, ambiental, paisajístico y/o deportivo) y luego los atributos que pueden ser (dinámica, utilización, accesibilidad y equipamiento turístico), cada criterio tiene una escala valorativa del 1 al 3 (1=moderado, $2=$ importante, $3=$ muy importante), cuya sumativa genera la valoración de potencialidad del sitio o emprendimiento. (Cuadro 2) 
Dom. Cien., ISSN: 2477-8818

Vol. 4, núm. 2, abril, 2018, pp. 81-102

Modelo de gestión para el turismo rural en la zona centro de Manabí, Ecuador

Cuadro 2. Matriz de potencialidades

\begin{tabular}{|c|c|c|c|c|c|c|c|c|c|c|}
\hline \multirow{2}{*}{ N. ${ }^{\circ}$} & \multirow{2}{*}{ Atractivo y / o recurso } & \multicolumn{4}{|c|}{ Carácter } & \multicolumn{4}{|c|}{ Atributos } & \multirow{2}{*}{ Tota } \\
\hline & & $\mathrm{C}$ & $\mathrm{A}$ & $\mathrm{P}$ & $\mathrm{D}$ & $\mathrm{D}$ & $\mathrm{U}$ & $\mathrm{A}$ & $\mathrm{E}$ & \\
\hline 1 & Finca Café Color Tierra & 2 & 2 & 2 & 2 & 2 & 3 & 2 & 3 & 18 \\
\hline 2 & Finca Sarita & 1 & 2 & 2 & 1 & 2 & 3 & 2 & 2 & 15 \\
\hline 3 & Finca La Fanesca & 1 & 2 & 1 & 1 & 1 & 2 & 2 & 2 & 12 \\
\hline 4 & Hacienda La Esperanza & 1 & 1 & 1 & 1 & 1 & 2 & 2 & 2 & 11 \\
\hline 5 & Finca El Jardín & 1 & 1 & 2 & 1 & 1 & 2 & 2 & 1 & 11 \\
\hline 6 & Producción de Caña de azúcar & 2 & 1 & 1 & 1 & 2 & 3 & 2 & 2 & 14 \\
\hline 7 & Finca La Favorita & 1 & 1 & 1 & 2 & 1 & 1 & 1 & 2 & 10 \\
\hline
\end{tabular}

Basados en la matriz de potencialidades, se identificó que las fincas Café Color Tierra, Sarita mantienen mayor potencial, y con un menor índice la fábrica de producción de caña de azúcar. Dichos recursos se encuentran con mayor potencial debido a las cualidades que ofrece el entorno y a la mayor afluencia de visitantes interesados de disfrutar sus riquezas, ya sean estas naturales o culturales. Considerando que la puntuación ascendente o igual a catorce se los reconoce de mayor potencial, mientras que los descendentes o igual a trece son de reconocimiento en potencial emergente como se muestra (Cuadro 3).

Cuadro 3. Resultado de potencialidades

\begin{tabular}{|c|c|c|}
\hline Recursos & Valor & Potencialidad \\
\hline Finca Café Color Tierra & 18 & Mayor potencial \\
\hline Finca Sarita & 15 & \\
\hline Producción de caña de Azúcar & 14 & \multirow{2}{*}{ Potencial emergente } \\
\hline Finca La Fanesca & 12 & \\
\hline Hacienda La Esperanza & 11 & \\
\hline Finca El Jardín & 11 & \\
\hline Finca La Favorita & 10 & \\
\hline
\end{tabular}


Modelo de gestión para el turismo rural en la zona centro de Manabí, Ecuador

Para conocer la realidad turística de la zona de estudio se procedió a realizar la matriz FODA, herramienta que sirvió para especificar de manera detallada las fortalezas y debilidades que posee la gestión turística rural en el área de estudio. Con el fin de ofrecer una visión clara sobre la situación del mismo, para el efecto se evaluaron las principales fortalezas, amenazas, debilidades y oportunidades; dando como resultado las siguientes: (Cuadro 4)

Cuadro 4. Principales variables de la matriz FODA

\begin{tabular}{|c|c|c|}
\hline Fortaleza & F1 & Producción agrícola y ganadera \\
\hline Oportunidad & O1 & Apoyo del MINTUR y Gobierno Provincial \\
\hline Debilidades & D2 & Limitado aprovechamiento de recursos naturales y culturales \\
\hline Amenaza & A2 & Baja inversión económica para el desarrollo de la actividad turística rural \\
\hline
\end{tabular}

Por tal motivo se establecieron estrategias de reorientación, las mismas que permiten minimizar las debilidades, aprovechando las oportunidades con el fin de contrarrestar las principales falencias.

\section{Fase II. Principios e indicadores de gestión sostenible}

Para la determinación de los principios e indicadores de gestión, se tomó como referencia los criterios del ITR (Instituto de Turismo Responsable) (s.f), donde mencionan los criterios globales de turismo sostenible que cualquier empresa o destino turístico debe cumplir para proteger y sostener los recursos naturales y culturales, ya que es una herramienta potencial para la mejora de la calidad de vida de las comunidades y sobre todo de la conservación, complementado con los criterios de gestión ambiental de Bermeo (s/f); se seleccionaron principalmente aquellos que se encuentran mayormente ligados al turismo rural; apoyados con la revisión bibliográfica y la observación directa; además de los criterios obtenidos por los actores involucrados en esta investigación (Cuadro 5).

Cuadro 5. Matriz de sistemas de indicadores

\begin{tabular}{|c|c|l|}
\hline Tipo de indicadores & Detalle de indicadores & \multicolumn{1}{c|}{ Incidencia } \\
\hline \multirow{2}{*}{ Indicadores sociales } & Acceso a servicios Básicos & Es completamente accesible a las comunidades donde se \\
& & $\begin{array}{l}\text { encuentran los sitios de interés turístico, a diferencia de la } \\
\text { finca El Jardín donde existen problemas en el sistema de }\end{array}$ \\
\hline
\end{tabular}

\section{1} Vol. 4, núm. 2, abril, 2018, pp. 81-102 
Dom. Cien., ISSN: 2477-8818

Vol. 4, núm. 2, abril, 2018, pp. 81-102

Modelo de gestión para el turismo rural en la zona centro de Manabí, Ecuador

\begin{tabular}{|c|c|c|}
\hline & & $\begin{array}{l}\text { riego debido a los estragos del terremoto del } 16^{a} \text { y la falta de } \\
\text { mantenimiento. }\end{array}$ \\
\hline & $\begin{array}{l}\text { Acceso a sistemas de } \\
\text { movilidad }\end{array}$ & $\begin{array}{l}\text { Los destinos turísticos enmarcados en el territorio de estudio } \\
\text { son netamente accesibles, aunque existen recursos no } \\
\text { desarrollados donde es difícil la accesibilidad. Además de la } \\
\text { presencia de caminos pocos adecuados para el desarrollo de } \\
\text { la actividad turística. }\end{array}$ \\
\hline & Identidad cultural & $\begin{array}{l}\text { La identidad cultural de los pueblos se basa principalmente } \\
\text { en las actividades desarrolladas por los ancestros que aún } \\
\text { mantienen vivas sus tradiciones. Y de ciertas familias que } \\
\text { ven esto como una oportunidad de desarrollo como es el caso } \\
\text { de la elaboración de productos derivados de la caña de } \\
\text { azúcar. Además de sitios turísticos en el que muestran las } \\
\text { labores del campo. }\end{array}$ \\
\hline & Seguridad pública local & $\begin{array}{l}\text { La seguridad de los destinos se mantiene de manera } \\
\text { considerable por lo que no existen muchas situaciones de } \\
\text { peligro, sin embargo, hay que mantener la cautela en todo } \\
\text { momento. }\end{array}$ \\
\hline & Pobreza y migración & $\begin{array}{l}\text { Las actividades del campo hacen que las personas se } \\
\text { mantengan de manera óptima, mientras que la migración } \\
\text { viene principalmente de los jóvenes que buscan nuevas } \\
\text { alternativas de desarrollo. }\end{array}$ \\
\hline & Intervención participativa & $\begin{array}{l}\text { Se ve reflejada en el entusiasmo y deseos de superación, en } \\
\text { especial de aquellas familias que buscan sustento } \\
\text { económico, aprovechando sus recursos tangibles e } \\
\text { intangibles. }\end{array}$ \\
\hline & $\begin{array}{l}\text { Satisfacción de los turistas o } \\
\text { visitantes }\end{array}$ & $\begin{array}{l}\text { Se basa principalmente en la interacción con la naturaleza y } \\
\text { las actividades del entorno, aunque cabe recalcar que se } \\
\text { necesita de mayor vinculación con la comunidad. }\end{array}$ \\
\hline \multirow[t]{2}{*}{$\begin{array}{l}\text { Indicadores } \\
\text { económicos }\end{array}$} & Estacionalidad del turismo & $\begin{array}{l}\text { La estacionalidad hace que los lugares turísticos sean menos } \\
\text { demandados, aunque si bien es cierto ayuda a la innovación } \\
\text { de nuevas alternativas para el ingreso económico yprogreso } \\
\text { de los destinos. }\end{array}$ \\
\hline & $\begin{array}{l}\text { Incremento de fuentes de } \\
\text { empleo }\end{array}$ & $\begin{array}{l}\text { La actividad turística contribuye a la dinamización de la } \\
\text { economía, siendo uno de las principales oportunidades en el } \\
\text { desarrollo de las comunidades rurales y la localidad en } \\
\text { general. }\end{array}$ \\
\hline
\end{tabular}

\section{2}

Vol. 4, núm. 2, abril, 2018, pp. 81-102

Jhonny P. Bayas Escudero, María C. Mendoza Torres 
Dom. Cien., ISSN: 2477-8818

Vol. 4, núm. 2, abril, 2018, pp. 81-102

Modelo de gestión para el turismo rural en la zona centro de Manabí, Ecuador

\begin{tabular}{|c|c|c|}
\hline & $\begin{array}{c}\text { Impulsa servicios turísticos } \\
\text { locales }\end{array}$ & $\begin{array}{l}\text { La dinamización del turismo mueve muchas plazas de } \\
\text { trabajo, ya que al generar movimiento en el mercado } \\
\text { turístico, indirectamente atrae la comercialización en los } \\
\text { destinos. Además de la innovación por ofrecer nuevos y } \\
\text { mejores servicios. }\end{array}$ \\
\hline & $\begin{array}{l}\text { Manejo de información sobre } \\
\text { registro de visitantes }\end{array}$ & $\begin{array}{l}\text { Es un indicador muy importante para la economía debido que } \\
\text { al tener el conocimiento de la demanda turística y el flujo de } \\
\text { visitantes se puede llevar un cálculo adecuado de ingresos. }\end{array}$ \\
\hline & Inversión económica & $\begin{array}{l}\text { La inversión forma parte del progreso, ya sea para brindar un } \\
\text { mejor servicio y obtener mayores ingresos. Aunque en } \\
\text { ciertos casos no existe mayor preocupación por } \\
\text { emprendedores de sitios de interés. }\end{array}$ \\
\hline \multirow[t]{8}{*}{$\begin{array}{l}\text { Indicadores } \\
\text { ambientales }\end{array}$} & $\begin{array}{c}\text { Conservación y protección de } \\
\text { especies en el entorno }\end{array}$ & $\begin{array}{l}\text { Existe bajo impacto de las especies debido a la considerable } \\
\text { afluencia de visitantes; aunque los desastres naturales } \\
\text { pueden ser un factor limitante de protección de los recursos. }\end{array}$ \\
\hline & $\begin{array}{c}\text { Gestión de residuos sólidos } \\
\text { (reciclaje) }\end{array}$ & $\begin{array}{l}\text { Los residuos sólidos se manejan de manera correcta, ya que } \\
\text { llevan un proceso adecuado de los desechos orgánicos e } \\
\text { inorgánicos en cada uno de los sitios de interés que se } \\
\text { encuentran mayormente desarrollados. }\end{array}$ \\
\hline & $\begin{array}{c}\text { Contaminación acústica y } \\
\text { atmosférica }\end{array}$ & $\begin{array}{l}\text { Debido al correcto reciclaje de residuos no existe mayor } \\
\text { contaminación acústica y atmosférica generada desde los } \\
\text { sitios rurales de interés turístico. }\end{array}$ \\
\hline & $\begin{array}{l}\text { Contaminación visual y } \\
\text { auditiva }\end{array}$ & $\begin{array}{l}\text { Es poco frecuente debido a los grupos pequeños que llegan a } \\
\text { los lugares. }\end{array}$ \\
\hline & $\begin{array}{c}\text { Control de capacidad de } \\
\text { carga }\end{array}$ & $\begin{array}{l}\text { La capacidad de carga es óptima respecto a los pequeños } \\
\text { grupos que ingresan a las comunidades rurales. Aunque sería } \\
\text { adecuado el seguimiento de ingresos. }\end{array}$ \\
\hline & Educación ambiental & $\begin{array}{l}\text { En los destinos turísticos no se brindan capacitaciones sobre } \\
\text { la preservación al medio ambiente, ya sean a los pobladores } \\
\text { de las comunas y visitantes que llegan a estas. }\end{array}$ \\
\hline & $\begin{array}{l}\text { Construcciones amigables con } \\
\text { el medio ambiente }\end{array}$ & $\begin{array}{l}\text { Por lo general en los destinos turísticos rurales se mantienen } \\
\text { construcciones de cabañas y demás instalaciones y } \\
\text { equipamiento con materiales hechos a base de madera o } \\
\text { caña; además de los procesos que se llevan a cabo para } \\
\text { coadyuvar a la protección del medio ambiente. }\end{array}$ \\
\hline & $\begin{array}{l}\text { Inclusión del visitante con la } \\
\text { recuperación del medio }\end{array}$ & $\begin{array}{l}\text { Las actividades a ejercer son netamente comprometedoras } \\
\text { con la comunidad y el bienestar ecológico, ya que se trata de }\end{array}$ \\
\hline
\end{tabular}


Dom. Cien., ISSN: $2477-8818$

Vol. 4, núm. 2, abril, 2018, pp. 81-102

Modelo de gestión para el turismo rural en la zona centro de Manabí, Ecuador

\begin{tabular}{|l|l|l|}
\hline & & $\begin{array}{l}\text { plantaciones y procesos de cultivo; además de la interacción } \\
\text { de las propiedades que brinda la naturaleza. }\end{array}$ \\
\hline
\end{tabular}

Se plantearon los criterios que permitan el control de los beneficios para los habitantes locales y asimismo los impactos ambientales que se generen por dicha actividad. Para efecto se determinaron las acciones a realizar y los medios de verificación que aporten al correcto proceso de seguimiento, donde se detallaron los posibles responsables de cada actividad. (Cuadro 6).

Cuadro 6. Verificación de indicadores

\begin{tabular}{|c|c|c|c|c|}
\hline Indicadores & Actividades & Medios de verificación & Responsables & \\
\hline $\begin{array}{l}\text { Estacionalidad } \\
\text { del turismo }\end{array}$ & $\begin{array}{ll}\text { - } & \text { Eventos donde interactúe la } \\
\text { comunidad y los turistas } \\
\text { - } & \text { Formación de paquetes o } \\
\text { recorridos }\end{array}$ & $\begin{array}{ll}- & \text { Informe de planificación de } \\
\text { - } & \text { los eventos } \\
- & \text { Informes técnicos } \\
- & \text { Informe de actividades } \\
- & \text { Videos } \\
\text { - } & \text { Guiones turísticos }\end{array}$ & $\begin{array}{ll}\text { - } & \text { Presidente de comuna } \\
\text { - } & \text { Propietarios } \\
& \text { emprendimientos } \\
\text { - } & \text { Instructores de eventos } \\
\text { - } & \text { GAD cantonal } \\
\text { - } & \text { Presidente de comuna } \\
\text { - } & \text { Propietarios } \\
& \text { emprendimientos }\end{array}$ & de \\
\hline $\begin{array}{l}\text { Satisfacción de } \\
\text { los turistas o } \\
\text { visitantes }\end{array}$ & $\begin{array}{ll}\text { - } & \text { Registro de la demanda } \\
\text { turística }\end{array}$ & $\begin{array}{ll}\text { - } & \text { Encuestas de evaluación de los } \\
\text { servicios y actividades }\end{array}$ & $\begin{array}{ll}- & \text { Presidente de comuna } \\
- & \text { Propietarios } \\
& \text { emprendimientos }\end{array}$ & de \\
\hline $\begin{array}{l}\text { Conservación y } \\
\text { protección del } \\
\text { entorno }\end{array}$ & $\begin{array}{ll}\text { - } & \text { Planes de manejo ambiental } \\
\text { - } & \text { Control de capacidad de } \\
\text { carga } \\
\text { - } & \text { Capacitaciones ambientales } \\
\text { - } & \text { Cuidado ambiental }\end{array}$ & $\begin{array}{ll}- & \text { Informe técnico } \\
- & \text { Informe de planificación de } \\
\text { las capacitaciones } \\
\text { - } & \text { Fotografías } \\
\text { - } & \text { Registro de visitantes }\end{array}$ & $\begin{array}{ll}\text { - } & \text { GAD cantonal } \\
\text { - } & \text { Presidente de comuna } \\
\text { - } & \text { Propietarios } \\
& \text { emprendimientos } \\
\text { - } & \text { Instructores de talleres }\end{array}$ & de \\
\hline $\begin{array}{l}\text { Gestión de } \\
\text { residuos sólidos }\end{array}$ & $\begin{array}{ll}\text { - } & \text { Inclusión del visitante con la } \\
\text { recuperación del medio } \\
\text { - } \\
\text { Reciclaje y proceso de } \\
\text { residuos }\end{array}$ & $\begin{array}{ll}- & \text { Fichas de registro } \\
- & \text { Fotografias } \\
- & \text { Informe }\end{array}$ & $\begin{array}{ll}\text { - } & \text { GAD cantonal } \\
- & \text { Presidente de comuna } \\
\text { - } & \text { Propietarios } \\
& \text { emprendimientos } \\
\text { - } & \text { Instructores de talleres }\end{array}$ & le \\
\hline
\end{tabular}

\section{Fase III. Modelo de gestión turística}

Para el modelo de gestión se establecieron objetivos, misión, visión, valores y metas corporativas los cuales son coherentes con la propuesta de una gestión basada en los principios de la sostenibilidad (cuadro 7).

Vol. 4, núm. 2, abril, 2018, pp. 81-102

Jhonny P. Bayas Escudero, María C. Mendoza Torres 
Dom. Cien., ISSN: 2477-8818

Vol. 4, núm. 2, abril, 2018, pp. 81-102

Modelo de gestión para el turismo rural en la zona centro de Manabí, Ecuador

Cuadro 7. Valores Corporativos

\begin{tabular}{|c|c|c|c|c|}
\hline Objetivo & Misión & Visión & Valores & Metas \\
\hline Optimizar el uso & Desarrollar los & Dentro de cinco & Eficiencia: Cumplimiento de & Desarrollo y sostenibilidad \\
\hline de los recursos & procesos de & años la zona & los objetivos trazados con & para los emprendimientos \\
\hline turísticos que & gestión en las & centro de & menores gastos de los recursos & turísticos rurales \\
\hline permita & actividades & Manabí será un & en relación a la productividad y & Brindar un servicio de \\
\hline incrementar la & turísticas, de tal & modelo de & el tiempo. & calidad. \\
\hline afluencia de & manera que se & desarrollo de & Eficacia: Cumplimiento de los & Identificación de las \\
\hline visitantes, como & contribuya al & turismo rural & objetivos trazados teniendo en & necesidades de las \\
\hline efecto de un plan & desarrollo y & basado en una & cuenta la misión y visión del & comunidades. \\
\hline de sostenibilidad & fomento turístico & adecuada & proyecto. & Fortalecer la confianza en los \\
\hline turística, & de la zona rural en & planificación y & Responsabilidad: Cumplir con & procesos de gestión para el \\
\hline brindando una & $\operatorname{los}$ & gestión, & las tareas encomendadas de & desarrollo turístico en las \\
\hline atención de & emprendimientos & brindando & acuerdo a cada área de trabajo. & zonas rurales. \\
\hline calidad, & destacados en el & servicios de & Gestión responsable: & Fomentar el turismo rural en \\
\hline aprovechando sus & centro de Manabí. & calidad para la & Mantener la inclusión de los & la zona centro de Manabí. \\
\hline riquezas & & satisfacción de & aspectos de sostenibilidad para & Dar un uso óptimo a los \\
\hline paisajísticas & & los turistas, & la gestión de las actividades, & recursos ya que son un \\
\hline promoviendo la & & facilitando el & contribuyendo a la satisfacción & elemento fundamental para el \\
\hline \multirow[t]{8}{*}{ sostenibilidad. } & & desarrollo & de los involucrados. & desarrollo turístico en las \\
\hline & & turístico. & Participación en la gestión: & zonas rurales. \\
\hline & & & Contribuir al desarrollo & Contribuir al desarrollo \\
\hline & & & progresivo y la aplicación & progresivo y la aplicación \\
\hline & & & sistemática de planes de & sistemática de planes de \\
\hline & & & formación social y profesional & formación social y \\
\hline & & & de las partes involucradas. & profesional de las partes \\
\hline & & & & involucradas. \\
\hline
\end{tabular}

95 Vol. 4, núm. 2, abril, 2018, pp. 81-102

Jhonny P. Bayas Escudero, María C. Mendoza Torres 
Dom. Cien., ISSN: 2477-8818

Vol. 4, núm. 2, abril, 2018, pp. 81-102

Calidad: Mantener el bienestar

social de las comunidades y la

demanda turística, siendo capaz

de ofertar y recibir un entorno

adecuado, tratos y servicios en

óptimas condiciones.

Además, se fijaron las estrategias que arrojo la aplicación de la matriz FODA; lo cual permitió establecer para cada estrategia un objetivo el cual se desglosa en actividades que faciliten el proceso de gestión (Cuadro 8).

Cuadro 8. Matriz de estrategias de gestión

$\begin{array}{ll}\text { Estrategia 1: Vincular normas intersectoriales que apoyen } & \text { Actividades: } \\ \text { el turismo rural. } & \text { 1. Realizar reuniones de vinculación entre actores. } \\ & \text { 2. Desarrollar mesas de trabajo para establecer metas y acciones }\end{array}$

Objetivo: Fortalecer el sector turístico rural a través de la participación constante de los actores.

Estrategia 2: Capacitar a los actores públicos y privados sobre la planificación y ejecución de proyectos.

Objetivo: Fortalecer el conocimiento del recurso humano sobre la gestión de los recursos turísticos.

\section{Actividades:}

1. Desarrollar talleres para determinar necesidades y requerimientos.

2. Realizar capacitaciones

3. Desarrollar proyectos conjuntos para el desarrollo de los emprendimientos participantes

\section{Actividades:}

1. Estructurar rutas, circuitos y productos específicos paralos emprendimientos participantes

2. Incluir actividades agropecuarias variadas con valor agregado.

Objetivo: Elaborar productos turísticos relacionados al turismo rural.

\section{Estrategia 4: Desarrollar sistemas de participación en} proyectos orientados a la sostenibilidad y buena práctica de los recursos turísticos.

Objetivo: Promover vínculos con instituciones educativas de tercer nivel y organismos de promoción turística nacional

\section{Actividades:}

1. Establecer vínculos con instituciones universitarias y de promoción nacional.

2. Establecer estrategias de acciones conjuntas para el desarrollo del turismo rural.

3. Participar en programas académicos y ferias de los emprendimientos.

96 Vol. 4, núm. 2, abril, 2018, pp. 81-102

Jhonny P. Bayas Escudero, María C. Mendoza Torres 
Dom. Cien., ISSN: $2477-8818$

Vol. 4, núm. 2, abril, 2018, pp. 81-102

Modelo de gestión para el turismo rural en la zona centro de Manabí, Ecuador

\begin{tabular}{ll}
\hline Estrategia 5: Gestionar financiamiento de los proyectos & Actividades: \\
turísticos con ONGs e instituciones financieras nacionales & 1. Diseñar proyectos de inversión \\
o internacionales. & 2. Establecer contactos con ONG's e instituciones financieras \\
& nacionales e internacionales \\
Objetivo: Promover el desarrollo turístico de los destinos & \\
en base a la inversión de los sectores. & \\
\hline
\end{tabular}

La operatividad del modelo de gestión se basó en la descripción de las acciones a ser desarrolladas de los entes relacionados a dicha particularidad. Por lo tanto, se presenta un organigrama destinado a las áreas que principalmente se deben considerar en los sitios de interés, con el propósito de llevar un mejor proceso en el área turística de tal manera que se vea reflejado en la satisfacción del turista o visitante (figura 1).

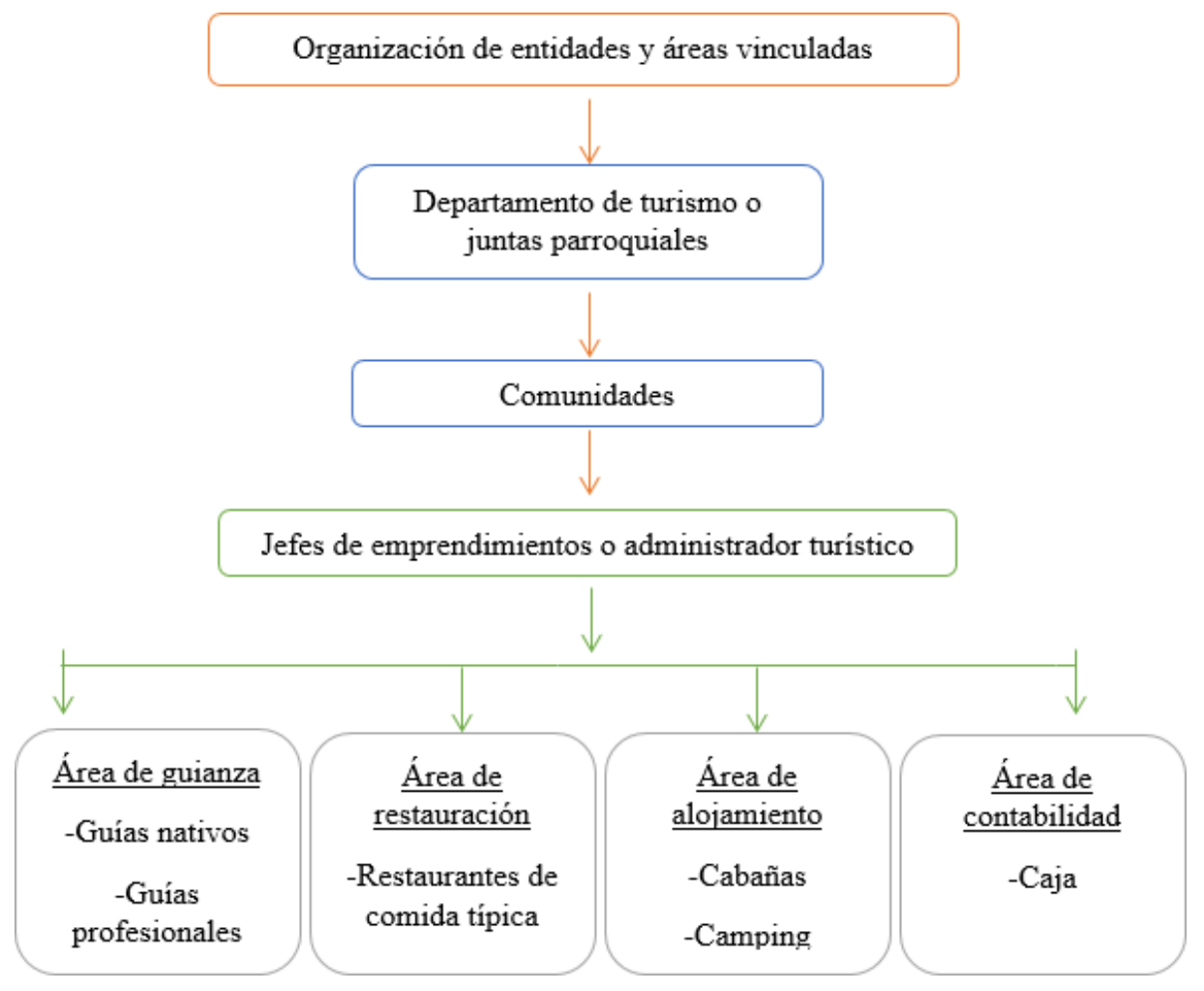

Figura 1. Operatividad del modelo

97 Vol. 4, núm. 2, abril, 2018, pp. 81-102

Jhonny P. Bayas Escudero, María C. Mendoza Torres 
Dom. Cien., ISSN: $2477-8818$

Vol. 4, núm. 2, abril, 2018, pp. 81-102

Modelo de gestión para el turismo rural en la zona centro de Manabí, Ecuador

Para determinar el buen funcionamiento de lo establecido en el modelo de gestión se necesita de la evaluación y control de los objetivos planteados a través de las estrategias consideradas anteriormente. Por lo cual se hace indispensable establecer las actividades, medios de verificación, el tiempo estimado para la realización de cada uno de ellos y sus respectivos responsables.

Dicho proceso sistemático se da con el propósito de comprobar los logros obtenidos durante el transcurso del trabajo en base a su aplicación, de tal manera que se lleve a cabo el seguimiento continuo para brindar una mejor calidad y satisfacción al turista (Cuadro 10).

Cuadro 10. Evaluación y Control

\begin{tabular}{|c|c|c|c|c|}
\hline Objetivos & Actividades & Verificación & Tiempo & Responsables \\
\hline $\begin{array}{c}\text { Fortalecer el sector } \\
\text { turístico rural a través de } \\
\text { la participación } \\
\text { constante de los actores. }\end{array}$ & $\begin{array}{l}\text { 1.-Realizar reuniones de } \\
\text { vinculación. } \\
\text { 2.- Desarrollar mesas de } \\
\text { trabajo para establecer } \\
\text { metas y acciones }\end{array}$ & $\begin{array}{c}\text { Informes. } \\
\text { Fotografías. } \\
\text { Revisión de contratos. } \\
\text { Registro de asistentes. } \\
\text { Encuestas de quejas y } \\
\text { sugerencias }\end{array}$ & Mensual & $\begin{array}{l}\text { Dirección de } \\
\text { turismo. }\end{array}$ \\
\hline $\begin{array}{c}\text { Fortalecer el } \\
\text { conocimiento del } \\
\text { recurso humano sobre la } \\
\text { gestión de los recursos } \\
\text { turísticos. }\end{array}$ & $\begin{array}{l}\text { 1.- Desarrollar talleres } \\
\text { para determinar } \\
\text { necesidades y } \\
\text { requerimientos. } \\
\text { 2.- Desarrollar proyectos } \\
\text { conjuntos para el } \\
\text { desarrollo de los } \\
\text { emprendimientos } \\
\text { participantes } \\
\text { 3.- Realizar capacitaciones }\end{array}$ & $\begin{array}{l}\text { Encuestas. } \\
\text { Fotografías. } \\
\text { Informes. }\end{array}$ & Mensual & $\begin{array}{l}\text { Dirección de } \\
\text { turismo } \\
\text { Administrador } \mathrm{t} .\end{array}$ \\
\hline $\begin{array}{c}\text { Elaborar productos } \\
\text { turísticos relacionados al } \\
\text { turismo rural, } \\
\text { aprovechando cada uno } \\
\text { de sus recursos y } \\
\text { servicios } \\
\text { complementarios. }\end{array}$ & $\begin{array}{c}\text { 1.- Estructurar rutas, } \\
\text { circuitos y productos } \\
\text { específicos para los } \\
\text { emprendimientos } \\
\text { participantes } \\
\text { 2.- Incluir actividades } \\
\text { agropecuarias variadas con } \\
\text { valor agregado. }\end{array}$ & $\begin{array}{c}\text { Cumplimiento de } \\
\text { itinerario. } \\
\text { Fotografias. } \\
\text { Registro de actividades } \\
\text { Encuestas. }\end{array}$ & $\begin{array}{c}\text { Diario- } \\
\text { Semanal }\end{array}$ & $\begin{array}{c}\text { Dirección de } \\
\text { turismo } \\
\text { Administrador t. } \\
\text { Guía turístico }\end{array}$ \\
\hline $\begin{array}{c}\text { Promover vínculos con } \\
\text { instituciones educativas } \\
\text { de tercer nivel. }\end{array}$ & $\begin{array}{c}\text { 1.- Establecer vínculos con } \\
\text { instituciones universitarias } \\
\text { y de promoción nacional } \\
\text { 2.- Establecer estrategias } \\
\text { de acciones para el } \\
\text { desarrollo del turismo } \\
\text { rural. }\end{array}$ & $\begin{array}{c}\text { Convenios } \\
\text { institucionales. } \\
\text { Informes técnicos. }\end{array}$ & $\begin{array}{c}\text { Semestral - } \\
\text { Anual }\end{array}$ & $\begin{array}{l}\text { Direcciones de } \\
\text { turismo. } \\
\text { Administrador t. } \\
\text { Instituciones } \\
\text { educativas. }\end{array}$ \\
\hline
\end{tabular}


Dom. Cien., ISSN: $2477-8818$

Vol. 4, núm. 2, abril, 2018, pp. 81-102

Modelo de gestión para el turismo rural en la zona centro de Manabí, Ecuador

3.-Participar en programas

académicos y ferias de los

emprendimientos.

\begin{tabular}{|c|c|c|c|c|}
\hline $\begin{array}{l}\text { Promover el desarrollo } \\
\text { turístico de los destinos } \\
\text { en base a la inversión de } \\
\text { los sectores }\end{array}$ & $\begin{array}{l}\text { 1.-Diseñar proyectos de } \\
\text { inversión } \\
\text { 2.- Establecer contactos } \\
\text { con ONG's e instituciones } \\
\text { financieras }\end{array}$ & $\begin{array}{c}\text { Hipotecas. } \\
\text { Certificados de } \\
\text { préstamos bancarios de } \\
\text { acorde a la actividad } \\
\text { turística o agraria }\end{array}$ & Anual & $\begin{array}{c}\text { Emprendedores o } \\
\text { administradores } \\
\text { turísticos }\end{array}$ \\
\hline
\end{tabular}

Por último, se aplicó el método de expertos con la finalidad de validar la propuesta; para lo se tomaron como referencia las opiniones de cinco expertos dentro del área de gestión turística, de los cuales solo cuatro realizaron observaciones en cuanto a la redacción y precisión de la propuesta del modelo de gestión. (Cuadro 11)

Cuadro 11. Criterio de Expertos

\begin{tabular}{|c|c|c|}
\hline $\mathrm{N}^{\circ}$ de expertos & Aspectos corregidos & Sugerencias \\
\hline \multirow{2}{*}{ Experto $N^{\circ} 1$} & Objetivo & Aspectos de redacción \\
\hline & Visión & Aspectos de redacción \\
\hline \multirow{3}{*}{ Experto $\mathrm{N}^{\circ} 2$} & Objetivo & Aspectos de redacción \\
\hline & Misión & Aspectos de redacción \\
\hline & Metas corporativas & Precisión \\
\hline \multirow{6}{*}{ Experto $\mathrm{N}^{\circ} 3$} & Objetivo & Aspectos de redacción \\
\hline & Misión & Aspectos de redacción \\
\hline & Visión & Aspectos de redacción \\
\hline & Valores corporativos & Aspectos de redacción \\
\hline & Metas corporativas & Aspectos de redacción \\
\hline & Estrategias & Precisión \\
\hline Experto $N^{\circ} 4$ & Objetivo & Aspectos de redacción \\
\hline
\end{tabular}




\section{Conclusiones}

- El modelo comprende la integración de la comunidad con los visitantes y gestores turísticos; de tal manera que se genera bienestar para la colectividad en general, sin dejar de lado la importancia de la sostenibilidad en el entorno. En el proceso de gestión los sectores rurales campesinos son parte de las estrategias sobre el desarrollo rural, ya que promueve y es aprovechada la actividad agropecuaria.

- El modelo se enfoca en mejorar la efíciencia del proceso de gestión rural, por lo que va más allá de la productividad económica cumpliendo con estándares de calidad, y el manejo sostenible de los recursos y la responsabilidad con el entorno social; es decir de llevar el cuidado del entorno natural y las comunidades donde se encuentran los emprendimientos turísticos.

- El modelo de gestión propone estrategias y acciones para la organización de las entidades públicas y privadas, ya que sirven de gran oportunidad para el desarrollo de los lugares turísticos rurales ubicados en la zona centro de la provincia, por último, se necesita de la evaluación y control de los objetivos planteados a través de las estrategias consideradas anteriormente para el buen funcionamiento de lo establecido en el modelo propuesto.

\section{Referencias Bibliográficas}

Avella, L. 2004. Manual de gestión comunitaria. Fases para la implementación de la gestión comunitaria. Colombia. 1:62-25

Ascanio, A. 2014. Modelo de gestión turística. Revista Papers de turismo: Turismo como sistema de servicios: Soportes físicos y estrategias. (6): 40-41

Bermeo, A. (s/f). Desarrollo sustentable de la República del Ecuador. 1-12

Balagué, J. y Navinés, F. 2012. Sistema de indicadores para la gestión sostenible de un destino turístico: Aplicación a la Costa Brava centro. Revista Harvard Deusto Business Research. 1(2): 134 136 
Modelo de gestión para el turismo rural en la zona centro de Manabí, Ecuador

Campos, B. y González, M. 2015. La gestión integral de un destino turístico: Mahahual, Costa Maya Quintana Roo, México. La importancia de los Indicadores de gestión integral del destino. 1: 39-42.

Domínguez, L., Batista, R. y Recompensa, C. 2013. Fundamentos necesarios para alcanzar el desarrollo socioeconómico local a través de la gestión turística patrimonial. Revista de Estudios Sociales. 15(29): 17-32.

Estrada, A. y Ranfla, A. 2015. La gestión del turismo comunitario versus desarrollo del turismo de masas en la región de Bahía de Banderas, Nayarit, México. Revista TURyDES 19

Flores, D. y Barroso, M. 2012. El turismo como estrategia de desarrollo rural sostenible. Revista Dialnet: El turismo como estrategia de desarrollo rural sostenible. (1): 59-83

Félix, G. y Doumet, Y. 2016. Teoría y práctica del Turismo Rural: casos de Planificación. Ecuador. $1: 89$.

ITR (Instituto de Turismo Responsable). S/f. Ecuador. Disponible en: http://media.firabcn.es/content/S029012/docs/Presentacions/SDF_ITR\%20Biosphere_aut.pdf

Moreno, A. 2012. La Planificación y Gestión Turística de Cuzco y Machu Picchu: Una aproximación desde el destino arqueológico considerando la relación con sus principales recursos. Revista TURyDES. 5: 1-28.

Merinero, R y Pulido, J. 2009. Desarrollo turístico y dinámica relacional. Metodología de análisis para la gestión activa de destinos turísticos. Revista de la Universidad de Murcia. (23):179

Agüera, F. y Morales, P. 2015. El ecoturismo como motor de desarrollo en zonas rurales: un estudio de caso en República Dominicana. Revista TURyDES. (19)

Plaza, D. 2013. Turismo rural como actividad dinamizadora del desarrollo local en la comuna de Curicó. Memoria para optar al título de Geógrafa. Chile. 28-39 
Reyes, M. Manjarrez, N. Ortega, A. 2014. La gestión del turismo comunitario en el marco de la economía popular y solidaria en Ecuador. Revista TURyDES: Turismo y Desarrollo. (17)

Sánchez, J. 2014. Propuesta de matriz para evaluación de proyectos geoparques en América Latina, con base en Áreas Naturales Protegidas: Aplicación y Casos de Estudio. Ecuador: Revista Pasos. $12(2): 384$

Villegas, F. 2000. Recursos turísticos y actividad del sector en la provincia de Granada. Cuadernos Geográficos. (30): 205-206 